\title{
Use of CT-Based Scoring System in Assessment of Pancreatitis Severity
}

\author{
Madina Ermekova ${ }^{1^{*}}$ \\ Karaganda State Medical University, Gogol Street 40, Karagandy 100000, Kazakhstan
}

\begin{abstract}
Citation: Ermekova M. Use of CT-Based Scorin System in Assessment of Pancreatitis Severity. Ope
Access Maced J Med Sci. 2019 Access://doi.org/10.3889/oamjms.2019.597

Keywords: Pancreatitis: Multiple organ failure; Severity Keywords: Pancreatitis; Multiple organ failure; Severity Computerized tomography of pancreatitis *Correspondence: Madina Ermekova. Bukhar-Zhyra avenue Building 29 Apartment 27 avenue, Kara
100000 Kazakhstan. E-mail: er-madina@yandex.ru

Received: 07-Oct-2019; Revised: 04-Nov-2019; Accepted: 05-Nov-2019; Online first: 14-Nov-2019

Copyright: ๑ 2019 Madina Ermekova. This is an openaccess article distributed under the terms of the Creative Commons Attribution-NonCommercial 4.0 intenation

Funding: This research did not receive any financia

Competing Interests: The authors have declared that no competing interests exis
\end{abstract}

\begin{abstract}
BACKGROUND: Severity of AP is an important indicator of death rate, playing a crucial role in defining a correct dealing with a patient at his/her initial admission, in deciding on the need to transfer a patient to the intensive care unit. Many studies point out a direct relation between the death rate and the number of affected organs. In light of this, looking for the new criteria of multiple organ failure is still useful in clinical practice. Typically, assessment of multiple organ failure with patients undergoing treatment in the intensive care unit is carried out with the use of various integrated scores based both on clinical laboratory assessment of patient's condition and on data obtained by advanced imaging methods. However, many scientists point out that the facilities of diagnostic radiology, including in particularly computerised tomography, are not used to the full extent.
\end{abstract}

AIM: We developed a CT score for assessment of pancreatitis severity that takes into consideration not only alterations of the pancreas but also enables evaluation of multiple organ failure with the examined patients.

METHODS: We have examined 100 patients with suspected pancreatitis. Among them 30 patients had pancreatitis without alterations of the vital organs; 70 patients had alterations of the vital organs, suffered organ or multiple organ failure and received treatment in the surgery unit and intensive care unit of the Department of Surgical Conditions of Karaganda Medical University.

RESULTS: Because of CT results, based on the proposed score, we assessed a degree of pancreas necrosis analysed the relation between organ failure and degree of pancreas necrosis. Finally, we evaluated the connection between multiple organ failure and the specific failure of one organ and the presence of necrosis and death rate.

CONCLUSION: The proposed score for CT-based assessment of pancreatitis severity can be used not only for identification but also for prediction of organ failure at the early stage of pancreatitis to a high accuracy as compared to conventional CT systems for assessment of the condition of patients affected by pancreatitis. It can also be used to differentiate the severity of organ failure and the number of affected organs.

\section{Introduction}

Revision of classification of pancreatitis in Atlanta in 2012 facilitated a broader view of pancreatitis as a pathology that causes death by affecting not just the pancreas itself but the surrounding vital organs as well, which is called multiple organ failure [1], [2]. The revised criteria (Atlanta - 2012) define multiple organ failure as a result of the failure of two or more organs or systems assessed using the modified Marshall score. According to data of the guidelines for the treatment of pancreatitis, multiple organ failure persisting for 24 hours after admission is one of the criteria defining pancreatitis severity [3].

The severity of AP course is an important indicator of death rate playing a crucial role in defining a correct dealing with a patient at his/her initial admission, in deciding on the need to transfer a patient to the intensive care unit. Many studies point out a direct relation between the death rate and the number of affected organs [4].

Adequate assessment of the severity of the patient's condition at the time of diagnosing AP increases the likelihood of correct treatment and improves the prognosis [5]. Clinical practice guidelines of the American College of Gastroenterology, 2013 specify the need to carry out assessment of severity 
of patient's condition immediately after determining the diagnosis and to repeat it over time, especially within 48 hours, and state the following: AP severity assessment should be carried out for stratification of patients and facilitating sorting because patients with multiple organ failure should be moved to the intensive care unit [6].

All reviewed clinical practise guidelines indicate that two approaches are used in clinical practice to assess expected response to treatment of AP. The first one is based on using various integrated scores, and the second one is based on using individual laboratory findings. At the same time, it is pointed out that new scores for determining severity and prognosis of AP, such as Marshall Score, did not allow for more accurate estimation of disease outcome. [7].

For these reasons, searching for new criteria for multiple organ failure is still useful in clinical practice. [6] There are various surgical assessment scores such as Ranson APACHE-II, MODS 2 and Glasgow that enable determining the severity of patient's condition, the likelihood of the fatal outcome, the intensity of biochemical alterations. The extent of consciousness impairment is assessed using the Glasgow score, and development of multiple organ failure is assessed using the MODS 2 score [8], [9], [10].

The principal disadvantages of these scores for determining the outcome of AP are the need to study various parameters within 24-48 hours. Because the first 12-24 hours from the point of patient's admission play the key role in selecting a treatment approach, and it is this very period that has a high risk of developing multiple organ failure, the BISAP score was developed (The Bedside Index for Severity in Acute Pancreatitis). The BISAP score index is calculated as a total of signs identified within 24 hours: Blood Urea Nitrogen exceeding $25 \mathrm{mg} / \mathrm{l}$, impaired mental status, signs of the systemic inflammatory response, pleural effusion present and age over 60 years [9].

Typically, APACHE-II, Marshall and SOFA scores are used for assessment of multiple organ failure with patients that undergo treatment in intensive care units. SAPS (Simplified Acute Physiology Score) may also be used to evaluate patients' condition severity. This score is not specific and allows prediction of course of any inflammatory disease based on an assessment of intoxication severity that plays an important role during the development of organ dysfunction [11], [12]. The majority of multiple-factor specific scores for assessment of the severity of acute pancreatitis include an integrated assessment of clinical and laboratory data. High diagnostic value of some signs explains their presence in several scores [8], [9], [10], [11], [12].

In the course of studies, in addition to scores based on clinical and laboratory assessment, other scores are also used that are based on advanced imaging methods. According to data of the American College of Gastroenterology, 2013 and Japanese recommendations on treatment of acute pancreatitis, 2015, CT is generally agreed to be the golden standard in diagnosing pancreatitis, as it enables assessment of the condition of the pancreas and the surrounding areas [13]. Images play an important role in diagnosing acute pancreatitis by enabling determining a diagnosis or suggesting alternative diagnosis; help to establish the causes of pancreatitis, assist in the classification of disease' severity and identification of peripancreatic complications. Choice of a relevant imaging method depends on the reason for a study, on clinical symptoms, the time when symptoms started and on data of laboratory testing. However, to this day, the majority of researchers give preference to CT in various clinical situations [14].

Currently, there are different assessment systems used utilising information obtained utilising computerised tomography (CT Severity Index (CTSI), Modified CT Severity Index (MCTSI), Pancreas Size Index (PSI), Extrapancreatic Point (EP), assessment of Extrapancreatic inflammation on CT (EPIC - is assessed by presence of ascites, pleuritis and retroperitoneal and mesenteric oedema), assessment of mesenteric oedema and peritoneal fluid (MOPassessment of presence or absence of peritoneal oedema and/or mesenteric fluid), and Balthazar score. In total, it was pointed out that regardless of a method used; CT demonstrates a very high accuracy among estimation scores for severity prediction. There have not been any statistically significant differences between the predictive accuracy of CT and clinical estimation scores [15].

The most studied is the CTSI score that is based on the Ranson-Balthazar score. CTSI score lets assess the severity of acute pancreatitis informed by advanced methods of imaging of structural changes emerging in the pancreas and retroperitoneal fat associated with acute pancreatitis and pancreonecrosis. To get an assessment based on CTSI, a class of acute pancreatitis was identified using the Ranson-Balthazar score. Each class was assigned a certain number of points according to the technique based on the aggregate of clinical evidence and signs of change of pancreas. In addition to that, the extent of necrosis of pancreas parenchyma expressed as a percentage was taken into consideration.

Estimation scores based on data obtained through CT studies that are used in case of pancreatitis do not take into account condition of surrounding organs owing to the examined area being limited only by the pancreas and surrounding tissues within a small distance [16]. It was pointed out by many scientists that the facilities of computer-assisted diagnostics are not utilised to the full [17], [18]. 
In common with many researchers, we have developed a conviction that the existing systems of estimation scores, it appears, have reached their maximum effectiveness in the prediction of persistent organ failure in case of acute pancreatitis. Complex combinations of estimation scores are more accurate but cumbersome in use and, therefore, are limited in for clinical use. The need remains in the development of new approaches, which is acknowledged by scientists from many different countries [17], [18].

We were presented with an opportunity to assess the vital organs' condition during the performance of standard contrast-enhanced CT scanning.

Performance evaluation for clinical use of the integrated score (developed by us) for CT-based assessment of pancreatitis severity.

\section{Methods}

In the furtherance of the set goal, we had proposed to put together a score for severity assessment based on the presence of changes in the vital organs as revealed by CT scanning.

When choosing the areas of interest and the key points of diagnosing, we were guided by the following principles that we had defined in advance: 1. clear imaging, availability, reliability and repeatability of changes; 2. anatomical justification, consistency, correspondence to stages of changes, clinical evidence behind these changes (it is not my thinking, but it is generally recognised that infiltration is heavier than mere effusion - having a foundation for our inference); 3 . importance of these changes for pancreatitis confirmed by other researchers; 4 . ability to assess all of that staying within standard CT scanning and without increasing an effective dose and the number of intrusive manipulations; does not require additional testing and does not incur additional expenses on routine treatment of patients with acute pancreatitis; 5 . broad coverage of all changes of affected systems; 6. correspondence to existing clinical characteristics of pancreatitis severity; and 7 . possibility to be assessed by several doctors and within 12 hours to capture quick changes in patient's clinical course, and at the same time providing for reasonable real time prospective as well as retrospective clarification of data [19].

Taking into account that all studies of multiple organ failure examine condition of the same systems such as respiratory apparatus, hepatobiliary system, gastrointestinal tract, condition of kidneys and cardiovascular system, and also based on performed review of literature materials [19], [20], [21], [22], [23], we have identified 7 organs and systems that are of interest in this case. Changes in those organs and systems are visible when computerised tomography is done, and provide sufficient information on pathological changes in remote organs and systems occurring during pancreatitis.

Table 1: Score for CT-based assessment of pancreatitis severity

\begin{tabular}{|c|c|c|c|c|c|}
\hline Group & Organ & Points & & & \\
\hline No. & system & 0 & 1 & 2 & 3 \\
\hline 1 & Pancreas & $\begin{array}{l}\text { No } \\
\text { changes }\end{array}$ & $\begin{array}{l}\text { Inflammatory } \\
\text { changes of } \\
\text { pancreas }\end{array}$ & $\begin{array}{l}\text { Inflammatory } \\
\text { changes of } \\
\text { pancreas and } \\
\text { surrounding tissues }\end{array}$ & $\begin{array}{l}\text { Areas of } \\
\text { necrosis in } \\
\text { pancreas }\end{array}$ \\
\hline 2 & GIT & $\begin{array}{l}\text { No } \\
\text { changes }\end{array}$ & $\begin{array}{l}\text { Moderate } \\
\text { thickening of } \\
\text { intestinal walls, } \\
\text { lumen dilation }\end{array}$ & $\begin{array}{l}\text { Inhomogeneity in } \\
\text { the structure of the } \\
\text { intestinal wall, } \\
\text { dysperistalsis }\end{array}$ & $\begin{array}{l}\text { Indications of } \\
\text { intestinal } \\
\text { obstruction and } \\
\text { infiltration of } \\
\text { circumintestinal } \\
\text { fat tissue }\end{array}$ \\
\hline 3 & $\begin{array}{l}\text { Liver } \\
\text { and } \\
\text { spleen }\end{array}$ & $\begin{array}{l}\text { No } \\
\text { changes }\end{array}$ & $\begin{array}{l}\text { Dilation of the } \\
\text { common bile duct } \\
\text { and distal } \\
\text { segments of } \\
\text { hepatic ducts }\end{array}$ & $\begin{array}{l}\text { Changes in density } \\
\text { (transient difference } \\
\text { in liver density), } \\
\text { hepatomegaly, } \\
\text { splenomegaly }\end{array}$ & Ascites \\
\hline 4 & Lungs & $\begin{array}{l}\text { No } \\
\text { changes }\end{array}$ & $\begin{array}{l}\text { The prominence of } \\
\text { perihilar markings }\end{array}$ & $\begin{array}{l}\text { pneumatisation } \\
\text { (ground-glass), } \\
\text { pleural effusion }\end{array}$ & $\begin{array}{l}\text { Bronchopneum } \\
\text { onic infiltration }\end{array}$ \\
\hline 5 & Kidneys & $\begin{array}{l}\text { No } \\
\text { changes }\end{array}$ & $\begin{array}{l}\text { Decreased density } \\
\text { of parenchyma }\end{array}$ & $\begin{array}{l}\text { Change of kidneys } \\
\text { size }\end{array}$ & $\begin{array}{l}\text { Thinning of } \\
\text { kidney } \\
\text { parenchyma } \\
\text { and } \\
\text { hydronephrosis }\end{array}$ \\
\hline 6 & Vessels & $\begin{array}{l}\text { No } \\
\text { changes }\end{array}$ & $\begin{array}{l}\text { Changes of one } \\
\text { large vessel } \\
\text { (dilation, } \\
\text { thrombosis) }\end{array}$ & $\begin{array}{l}\text { Dilation of the portal } \\
\text { and splenic veins, } \\
\text { mesenteric vein }\end{array}$ & $\begin{array}{l}\text { The emergence } \\
\text { of } \\
\text { portosystemic } \\
\text { bypasses, } \\
\text { unstable } \\
\text { anastomosis, } \\
\text { thrombosis }\end{array}$ \\
\hline 7 & $\begin{array}{l}\text { Number } \\
\text { of } \\
\text { affected } \\
\text { systems }\end{array}$ & $\begin{array}{l}\text { Other } \\
\text { organs not } \\
\text { affected }\end{array}$ & 1 organ affected & 2 organs affected & $\begin{array}{l}3 \text { organs } \\
\text { affected }\end{array}$ \\
\hline
\end{tabular}

The image evaluation procedure was developed for the description of images.

1. Condition of examined organs is assessed at all stages of examination.

2. Measuring the diameter of intestinal lumen and lumen of vessels, as well as size of kidneys, is carried out using a digital measuring ruler.

3. Condition of liver parenchyma and spleen is assessed in the delayed phase.

4. Assessment of the condition of biliary tracts is carried out using the minimum intensity projection.

5. Density values of the liver, spleen, kidneys are determined using Hounsfield units.

6. Changes in lungs are assessed using the 'lung window'.

7. Vessel condition is assessed in the arterial and portal phase using the maximum intensity projection as well as volume representation for assessment of the condition of arteries and veins.

Tools specified below were used during the postprocessing stage. Most often, for assessment of parenchymal organs, we resorted to multiplanar reconstruction (MPR). Images in the maximum intensity projection (MIP reconstructions) were used for imaging of courses of vascular structures and identification of spontaneous portacaval bypasses. 
Volume Rendered Technique (VRT) images were used visual demonstration of vessel courses, their relations one with another and with the internals.

During the data postprocessing stage, we calculated volumes of liver and spleen using the 'Volume' software. On each partition, we outlined an organ of interest with the subsequent computer-aided calculation of its volume based on the modified Simpson's rule.

Then in 2017-2019, a single-centre randomised study was conducted at the premises of the Department of Surgery of non-commercial jointstock company Karaganda Medical University.

We have examined 100 patients with suspected pancreatitis. Among them 30 patients had pancreatitis without alterations of the vital organs; 70 patients had alterations of the vital organs, suffered organ or multiple organ failure and received treatment in the surgery unit and intensive care unit of the Department of Surgical Conditions of Karaganda Medical University.

The inclusion criteria were: patients of both genders at least 18 years old who were admitted to the in-patient hospital through emergency room diagnosed with acute pancreatitis during the $1^{\text {st }}$ stage of the disease. The criteria for exclusion from the study were: past medical history with diabetes mellitus and another endocrine, autoimmune, contagious, oncological diseases, existing serious concomitant cardiovascular morbidity, cardiac insufficiency, past medical history with allergic reactions and contrast agent intolerance, pregnancy. The patients were divided into two groups depending on being affected by organ failure within 24 hours after admission. Data related to age, gender, pancreatitis aetiology were analysed. Examined persons were assessed concerning the severity of their condition using estimation scores: Ranson, APACHE II, SOFA and Marshall. Following the CT results, we assessed the extent of pancreas necrosis, analysed the relation between organ failure and extent of pancreas necrosis and necrosis infection. And finally, we assessed the connection between multiple organ failure and the specific failure of one organ with the presence of necrosis and death rate. Exceedance of the 2 point threshold per the SOFA score signified dysfunction of an organ system.

All studies were performed using CT machines (Siemens Definition AS 64 and Toshiba Aquilion 64 slice CT Scanner) applying the standard CT conclusion for abdominal imaging. Then images were processed and reconstructed in the axis plane with a slice thickness of $5 \mathrm{~mm}$. All CT data obtained in our institute were reviewed independently of one another at two work stations with the aid of software Syngo-Imaging, version VB36A, Siemens Medical Solutions.

Two radiologists (the first author and the second author), having over 3 years of experience in abdominal radiology, carried out an independent check of all CT images without knowing any patient specifics and their clinical outcome. A result was considered to be final when both radiation therapists, independent of each other, reached the same conclusion concerning the presence of alterations and process severity. When CT results were controversial, the final result was achieved based on consensus. All patients had the Balthazar score points calculated and recorded based on a review of $C T$ images.

Continuous data were assessed using the $m$ test, and classified data were analysed using the $\chi^{2}$ test. The value was determined as $P<0.05$. Study results were subjected to mathematical and statistical processing. Variance analysis, descriptive statistics and correlation analysis methods were applied. For each studied quantitative variable calculations were carried out to determine the arithmetic mean value $(M)$, mean square deviation $(\sigma)$, mean error $(m)$. Significance of differences among the values was evaluated per the Student-Fischer test ( $t$ ). Significance point of the compared values was considered significant, where $p<0.05$. To assess the informative value of the estimation scores, we used the evidence-based medicine tests (responsiveness, specificity, the predictive accuracy of a positive and negative result, the diagnostic accuracy of the method).

Statistical processing was carried out using a personal computer and software Microsoft Excel XP and Statistica 6.0 for Windows.

\section{Results}

Among the 100 patients, 24 persons (24.0\%) revealed the presence of multiple organ failure (maximum of 5 organ systems) and 2 of them died; 46 patients revealed one organ failure. Out of the patients affected by one organ failure, 21 persons had a pulmonary failure, 11 persons had a hepatic failure, and 9 persons had a gastrointestinal loss. Still, 5 patients were diagnosed with renal failure, and in 4 cases, there were vascular changes. None of these patients' group died.

As for the frequency of different specific multiple organ failure, pulmonary upset took place in 20 cases, renal failure was found in 4 patients, circulatory insufficiency was found in 3 patients, hepatic failure - in 22 cases, and 12 persons had a gastrointestinal loss.

All patients had their Balthazar score points calculated and recorded based on a review of CT images. 
Table 2: Balthazar score

\begin{tabular}{lc}
\hline Score & Number \\
\hline A & 16 \\
B & 34 \\
C & 31 \\
D & 13 \\
E & 7 \\
\hline
\end{tabular}

Ranson and APACHE scores point to evaluate condition severity was also calculated for each patient.

Table 3: Severity assessment scores

\begin{tabular}{lcc}
\hline Severity assessment & & \\
\hline Ranson & $5(4-6)$ & $6(6-8.5)$ \\
APACHE & $16(13-21.8)$ & $26(18-30.8)$ \\
SOFA & $5(4-7)$ & $13(9-15.8)$ \\
Marshall & $3(2-5)$ & $9(8-10)$ \\
\hline
\end{tabular}

According to the obtained results, out of 100 persons, a total of 70 patients (70\%) demonstrated organ failure, of which 24 patients (24.0\%) had multiple organ failure, whereas 40 patients (40\%) had a functional abnormality of one organ system. Pulmonary failure is the most common organ abnormality (41\%) among failures of individual organs. We did not identify any relationship between the extent of necrosis and the presence of organ failure. Patients with organ failure had a higher death rate as compared with patients without organ failure. Death of two patients was related to multiple organ failure: lung affection, hepatic dysfunction and gastrointestinal dysfunction. According to the classification, the patients are distributed, as shown in Table 4.

Table 4: Classification of the patients

\begin{tabular}{lc}
\hline Per severity level & \\
\hline Light & 23 \\
Moderate & 34 \\
Severe & 43 \\
Died & 2 \\
\hline
\end{tabular}

However, it was noted that there is a relation between severity level according to the scores and death rate and multiple organ failure. Death rate and APACHE II score points were significantly higher with patients who had organ failure than with patients who did not have organ failure.

Nonetheless, the deceased patients had a much greater extent of multiple organ failure that expressed itself as a pulmonary failure, cardiovascular insufficiency and gastrointestinal affection as compared with the survived patients.

In the vast majority of cases, 86 patients (86\%), acute pancreatitis was not accompanied by the development of necrotic damage of pancreas; during imaging, pancreas condition corresponded to interstitial oedema. In 80 cases (80\%) where interstitial oedema of pancreas developed, peripancreatic infiltration was not identified. In $10 \%$ of observations (10 persons), interstitial oedema of the pancreas was accompanied by the development of infiltration in retroperitoneal space. Formation of peripancreatic infiltrates in the absence of signs of necrotising pancreatic affection is an adverse indicator in terms of prediction. When assessing the occurrence of infiltrating, in 13 cases (13\%) up to 3 anatomical locations were involved in the pathologic process. Only in $9 \%$ of cases ( 9 observations) infiltrate spread from 4 to 6 anatomical locations, and in isolated cases (2 observations) it was identified in 6 and more locations.

Table 5: CT data of the pancreas condition

\begin{tabular}{lc}
\hline Pancreas affection per CT data & Number \\
\hline Interstitial oedema & 86 \\
Fine-focal pancreonecrosis & 6 \\
Large-focal pancreonecrosis & 5 \\
Total pancreonecrosis & 3 \\
\hline
\end{tabular}

Fine-focal affection of pancreas tissue was observed with 6 patients (6\%). Of these 6 patients, in 5 cases we identified infiltration of up to 3 locations of retroperitoneal fat, and in 1 case infiltration was found in from 4 to 6 locations. Large-focal necrosis was identified with 5 patients (5\%), and in 4 observed cases, it was accompanied by involvement of $4-6$ locations of retroperitoneal fat into the pathologic process. Near-total affection was diagnosed in 3 observed persons ( $3 \%)$, and it was accompanied by peripancreatic infiltrate with the involvement of 6 or more anatomical locations into the process.

Table 6: Extent of peripancreatic infiltrate

\begin{tabular}{lc}
\hline Without the involvement of retroperitoneal fat & 80 \\
The affection of up to 3 locations & 13 \\
The affection of 4-6 locations & 5 \\
More than 6 locations & 2 \\
\hline
\end{tabular}

As extent of pancreas affection was determined, a strong direct correlation with amount of peripancreatic infiltrate was identified $(r S=0.78 ; p=$ $0.001)$.

Complications on the part of the vascular system in the $1^{\text {st }}$ stage of severe acute pancreatitis were registered in 7 cases $(7 \%)$. Acute renal failure was diagnosed with 9 patients (9\%). Most frequently, respiratory insufficiency was encountered that accompanied $41 \%$ of observations. The advance of acute respiratory insufficiency may be deemed to be a predictor of pancreonecrosis development. Development of hepatic insufficiency and GIT loss was noted with 33 and 21 patients (33\% and 21\%) respectively.

Development of early organ failure accompanied $82 \%$ cases of severe pancreatitis and significantly aggravated prediction and course of severe acute pancreatitis. Complications in two body systems were identified in $60 \%$ of observations; complications in more than two systems were in $40 \%$ of observations. Early organ failure during the $1^{\text {st }}$ stage of the disease was the cause of two fatal outcomes, which amounted to $4.65 \%$ of the total number of persons with severe acute pancreatitis. In this study, we have established that the frequency of organ failure rises with greater extent of necrosis. 
Table 7: Organ failure and multiple organ failure

\begin{tabular}{lccc}
\hline Affected organ & Moderate level & Severe level & Total \\
\hline Without organ failure & & & 30 \\
Organ failure & & & 46 \\
Multiple organ failure & & 20 & 24 \\
Lungs & 21 & 22 & 41 \\
Liver & 11 & 12 & 33 \\
GIT & 9 & 4 & 21 \\
Kidneys & 5 & 3 & 9 \\
Vessels & 4 & & 7 \\
\hline
\end{tabular}

\section{Discussion}

As the results of our study show, the proposed CT score for assessment of dysfunction of organs has demonstrated good accuracy and was comparable to APACHE II in the assessment of pancreatitis severity.

We must admit that our study has a series of limitations. Firstly, the study had a medium-sized group of examined persons. Our study covered only 100 patients. Secondly, we did our analysis only for the sub-group of patients with acute pancreatitis within a consecutive group of patients who had CT scanning within 24 hours after emerging of symptoms in the first three days after admission. Some patients with acute pancreatitis received treatment without CT scanning, which possibly contributed to a lower death rate in our group. These limitations could introduce inaccuracy into the results of our study.

Nonetheless, in concluding we would like to point out that following the results of this study the developed score for CT-based assessment of pancreatitis severity can be used not only for identification but also for prediction of failure of various organs at the early stage of pancreatitis to a high accuracy as compared with conventional CTbased systems for assessment of condition of patients with pancreatitis. It can also be used to differentiate the severity of organ failure and the number of affected organs.

\section{References}

1. Foster BR, Jensen KK, Bakis G, Shaaban AM, Coakley FV. Revised Atlanta classification for acute pancreatitis: a pictorial essay. Radiographics. 2016; 36(3):675-87. https://doi.org/10.1148/rg.2016150097 PMid:27163588

2. Acute Pancreatitis Classification Working Group. Classification of acute pancreatitis - 2012: revision of the Atlanta classification and definitions by international consensus. Gut. 2013; 62(1):10211. https://doi.org/10.1136/gutinl-2012-302779 PMid:23100216

3. Löhr JM, Dominguez-Munoz E, Rosendahl J, Besselink M, Mayerle J, Lerch MM, Haas S, Akisik F, Kartalis N, Iglesias-Garcia J, Keller J. United European Gastroenterology evidence-based guidelines for the diagnosis and therapy of chronic pancreatitis
(HaPanEU). United European gastroenterology journal. 2017; 5(2):153-99. https://doi.org/10.1177/2050640616684695 PMid:28344786 PMCid:PMC5349368

4. Shi N, Liu T, de la Iglesia-Garcia D, Deng L, Jin T, Lan L, Zhu P, Hu W, Zhou Z, Singh V, Dominguez-Munoz JE. Duration of organ failure impacts mortality in acute pancreatitis. Gut. 2019:gutjnl2019. https://doi.org/10.1136/gutjnl-2019-318241 PMid:31233394

5. Bollen TL, Singh VK, Maurer R, Repas K, van Es HW, Banks PA, Mortele KJ. Am J Gastroenterol. A comparative evaluation of radiologic and clinical scoring systems in the early prediction of severity in acute pancreatitis. 2012; 107(4):612-9. https://doi.org/10.1038/ajg.2011.438 PMid:22186977

6. Beganskaya LA, Kishkun AA. Diagnosis of acute pancreatitis from the perspective of evidence-based medicine. Emergency medical services. 2017; 4:23-26.

7. Tenner S, Baillie J, DeWitt J, Vege SS. American College of Gastroenterology. American College of Gastroenterology guideline: management of acute pancreatitis. Am. J. Gastroenterol. 2013; 108(9):1400-15. https://doi.org/10.1038/ajg.2013.218 PMid:23896955

8. Ushakov AA, Ovchinnikov VI, Babushkin DA. Predictive value of indicators for assessment of severity of acute pancreatitis.

International magazine of applied and fundamental studies. 2016; 4-4:721-723.

9. Vinnik YS, Dunaevskaya SS, Antufrieva DA. Diagnostic value of integral scoring systems in assessing the severity of acute pancreatitis and patient's condition. Vestnik Rossiiskoi akademii meditsinskikh nauk. 2015; (1):90-4. https://doi.org/10.15690/vramn.v70i1.1236 PMid:26027276

10. Sharma V, Rana SS, Sharma RK, Kang M, Gupta R, Bhasin DK.A study of radiological scoring system evaluating extrapancreatic inflammation with conventional radiological and clinical scores in predicting outcomes in acute pancreatitis. Ann Gastroenterol. 2015; 28(3):399-404

11. Vinnik YS, Dunaevskaya SS, Antyufrieva DA, Deulina VV. Endothelial dysfunction and development of organ failure in acute pancreatitis. Current Issues of Science and Education. 2018; 5.

12. Tee YS, Fang HY, Kuo IM, Lin YS, Huang SF, Yu MC. Serial evaluation of the SOFA score is reliable for predicting mortality in acute severe pancreatitis. Medicine. 2018; 97(7):e9654.

https://doi.org/10.1097/MD.0000000000009654 PMid:29443733 PMCid:PMC5839831

13. Litvin AA, Knyazeva EG, Filatov AA. Modern Classificatory CTbased Identification of Acute Pancreatitis. Journal of Radiology and Nuclear Medicine. 2018; 99(3). https://doi.org/10.20862/00424676-2018-99-3-164-170

14. Busireddy KK, AlObaidy M, Ramalho M, Kalubowila J Baodong L, Santagostino I, Semelka RC. Pancreatitis-imaging approach. World journal of gastrointestinal pathophysiology. 2014 5(3):252-270. https://doi.org/10.4291/wigp.v5.i3.252 PMid:25133027 PMCid:PMC4133524

15. Bollen TL, Singh VK, Maurer R, Repas K, van Es HW, Banks PA, Mortele KJ.A comparative evaluation of radiologic and clinical scoring systems in early prediction of severity in acute pancreatitis. Am J Gastroenterol. 2012; 107(4):612-9.

https://doi.org/10.1038/ajg.2011.438 PMid:22186977

16. Dunaevskaya SS, Antyufrieva DA. Prediction of Outcome in Severe Acute Pancreatitis. Postgraduate doctor. 2013; 1(56):203207.

17. Koutroumpakis E, Furlan A. Investigating the predictive role of computed tomography in patients with acute pancreatitis: let's not give up. Annals of gastroenterology. 2015:299--300.

18. Mounzer R, Langmead CJ, Wu BU, Evans AC, Bishehsari F, Muddana V, Singh VK, Slivka A, Whitcomb DC, Yadav D, Banks PA, Papachristou GI. Comparison of existing clinical scoring systems to predict persistent organ failure in patients with acute pancreatitis. Gastroenterology. 2012; 142(7):1476-82. https://doi.org/10.1053/i.gastro.2012.03.005 PMid:22425589

19. Wu BU, Batech M, Quezada M, Lew D, Fujikawa K, Kung J, 
Jamil LH, Chen W, Afghani E, Reicher S, Buxbaum J. Dynamic measurement of disease activity in acute pancreatitis: the pancreatitis activity scoring system. The American journal of gastroenterology. 2017; 112(7):1144-1152.

https://doi.org/10.1038/ajg.2017.114 PMid:28462914 PMCid:PMC5519418

20. Ikeura T, Horibe M, Sanui M, Sasaki M, Kuwagata Y, Nishi K, Kariya S, Sawano H, Goto T, Hamada T, Oda T. Validation of the efficacy of the prognostic factor score in the Japanese severity criteria for severe acute pancreatitis: A large multicenter study. United European Gastroenterol J. 2017; 5(3):389-397.

https://doi.org/10.1177/2050640616670566 PMid:28507751
PMCid:PMC5415216

21. Antyufrieva DA. Prediction of typical complications of acute pancreatitis depending on the phase of the disease: Krasnoyarsk, 2016.

22. Styazhkina SN, Krasnoperova OV, Kuznetsov SV, Gorshkov MS, Khazieva LD. Pathomorphological changes in internal organs with pancreatic necrosis. Synergy of Sciences. 2017; 11:613-617.

23. Mayorov VM, Dundarov ZA, Podolskiy AL. Morphological Changes of the Internal Organs in Acute Necrotizing Pancreatitis according to Autopsy. Surgery News. 2010; 5:28-36. 